\title{
V5 Desenvolvimento e validação de método alternativo para determinação de fósforo no polissacarídeo meningocócico A (PSA) e Polirribosil Ribitol Fosfato (PRRP)
}

\author{
Lauro de Sena Laurentino¹, Cláudio Dutra Figueira1 \\ ${ }^{1}$ Bio-Manguinhos, Fiocruz, RJ
}

Introdução: O PRRP, polirribosil-ribitol fosfato, é um polissacarídeo presente na formulação da vacina HIB e o PSA, polissacarídeo meningocócico $A$, é utilizado na formulação das vacinas meningocócicas $\mathrm{C}, \mathrm{AC}$ e ACW, todas produzidas por Bio-Manguinhos. Ambos os polissacarídeos apresentam o elemento fósforo em sua estrutura e sua quantificação é utilizada para determinar suas purezas através da relação estequiométrica entre a massa de fósforo e a massa total dos polissacarídeos. A técnica utilizada para quantificação de fósforo no laboratório Fisico-Químico do Departamento e Qualidade de Bio-Manguinhos é o método de Chen, método colorimétrico, desenvolvido e publicado em 1956. Como proposta de metodologia alternativa, foi desenvolvido um método de determinação de fósforo por espectroscopia de emissão atômica por plasma acoplado indutivamente (ICP-OES). Esta é uma técnica que apresenta como fonte de energia o plasma, que atinge temperaturas de $10000 \mathrm{~K}$, sendo capaz de excitar a maioria dos elementos químicos. Ao retornarem para seu estado fundamental, eles emitem radiação eletromagnética, em uma linha muito específica, e proporcional à concentração do elemento presente na amostra.

Objetivo: Desenvolver e validar uma metodologia alternativa para a quantificação de fósforo no polissacarídeo Meningocócico A (PSA) e no polirribosil-ribitol fosfato (PRRP) por ICP-OES.

Metodologia: Para a execução do método de Chen, as amostras são submetidas a um processo de digestão com uma mistura de ácido nítrico e ácido perclórico concentrados, à temperatura de $250^{\circ} \mathrm{C}$, sendo necessário aproximadamente 7 horas de análise. A etapa inicial do desenvolvimento do método por ICP-OES consistiu na avaliação do efeito de matriz para a quantificação do fósforo nos polissacarídeos. Testaram-se alguns métodos de digestão da amostra e também os parâmetros de análise no ICP-OES como, por exemplo, fluxo dos gases e os modos axial ou radial de análise. Após a etapa de desenvolvimento, foram avaliados os seguintes parâmetros de validação, baseados na RE n־899 de 2003, da ANVISA: precisão (repetitividade e precisão intermediária), exatidão, linearidade, especificidade e robustez.

Resultados: Todos os parâmetros de validação se encontraram dentro do exigido pela RE n요 de 2003, da ANVISA. Foi analisado o material de referência de PRRP e o resultado obtido pelo método de Chen foi 
$8,14 \%$ e pelo ICP-OES foi $8,29 \%$. Através do desenvolvimento da metodologia por ICP-OES, a quantificação de fósforo passou a ser realizada em no máximo 30 minutos, garantindo, através da validação realizada, um método altamente rápido, exato e repetitivo.

Conclusão: De acordo com os resultados obtidos, conclui-se que o método para determinação de fósforo por ICP-OES apresenta confiabilidade, além de proporcionar uma redução bastante significativa no tempo de análise. Além disso, essa nova metodologia diminui a exposição e o rejeito de reagentes tóxicos, uma vez que foi eliminado o processo de digestão e adição do reativo de coloração.

Palavras-Chave: Fósforo, PRRP, ICP-OES 